\title{
A INSERÇÃO SUBORDINADA DO BRASIL NA DIVISÃO \\ INTERNACIONAL DO TRABALHO: CONSEQUÊNCIAS TERRITORIAIS E PERSPECTIVAS EM TEMPOS DE GLOBALIZAÇÃO
}

\section{The subordinated insertion of Brazil in the international division of labour: territorial consequences and perspectives in globalization times}

Mirlei Fachini Vicente Pereira Professor Dr. do Instituto de Geografia da Universidade Federal de Uberlândia Uberlândia/MG - Brasil mirlei@ig.ufu.br

Artigo recebido para publicação em 07/01/2010 e aceito para publicação em 01/07/2010

RESUMO: $\quad$ A divisão internacional do trabalho resulta diretamente numa divisão territorial do trabalho que cada Estado nação acolhe em seu território, e é por isso que ela se torna tema de interesse e de importância na análise geográfica. O texto pretende avaliar as formas de inserção subordinada do Brasil na divisão internacional do trabalho, buscando compreender as consequências desta situação de subordinação para o território nacional.

Palavras-chave: Divisão Internacional do Trabalho. Divisão Territorial do Trabalho. Uso do Território. Brasil.

ABSTRACT: The international division of labour directly results in a territorial division of labour that each nation inserts in its territory. That is why this division is an interesting and important theme in geographical analysis. The text intends to evaluate the ways of subordinated insertion of Brazil in the international division of labour, aiming at understanding the consequences of this situation of subordination for the national territory.

Keywords: International Division of Labour. Terrritorial Division of Labour. Territory use. Brazil. 


\section{PARA UMA ANÁLISE GEOGRÁFICA DA DIVISÃO INTERNACIONAL DO TRABALHO}

A noção de divisão internacional do trabalho corresponde às funções produtivas desempenhadas por cada Estado nação no sistema internacional e, deste modo, está diretamente ligada a uma divisão do trabalho que também se dá no interior do território nacional (SANTOS, 1996, p.106). Trata-se de uma divisão do trabalho que é, ao mesmo tempo, também uma divisão e repartição dos recursos (materiais e imateriais) mobilizados nas atividades produtivas.

Do mesmo modo como a importância de cada agente produtivo é muito diferenciada no interior das formações sócio-espaciais, cada Estado-nacional também acolhe diferentes funções e trabalhos no sistema internacional da produção e das trocas, produzindo, a partir do empenho de diferentes recursos, feições territoriais bastante desiguais tanto quando tomamos como exemplo a configuração do espaço no interior de um território nacional (as diferenças regionais, por exemplo) ou quando comparamos a formação territorial de diferentes Estados nacionais.

No Brasil a sociedade e o território nacional historicamente se empenham num tipo de trabalho que é, em grande parte, requerido e exigido de fora do país. Este processo, com a natureza que ele assume no caso brasileiro, é importante para a compreensão das dinâmicas que orientam a formação socioespacial e a divisão territorial do trabalho.

Assim, algumas questões nos parecem fundamentais para a análise desta situação - quais agentes tiram proveito das funções desempenhadas pelo país no sistema econômico-produtivo internacional e quais as suas consequências para o território nacional? Quais as perspectivas do Brasil (e a função a ser desempenhada pelo país) na divisão internacional do trabalho neste início de século? Para que possamos realizar uma análise geográfica destas questões é necessário pensarmos como as participações do país na divisão internacional do trabalho atuam constantemente na produção e transformação de seus recursos e estruturas territoriais, ou seja: como regiões produtivas se formam (e se transformam) no território nacional para atender as demandas do mercado externo? E como a sociedade se insere, se adapta ou reage a este processo? Quais os recursos gerados? De que modo eles são apropriados pela nação?

\section{A FORMAÇÃO DO TERRITÓRIO BRASILEIRO COMO RESULTADO DA DIVISÃO INTERNACIO- NAL DO TRABALHO}

Baseado em Max. Sorre, Milton Santos reconheceu, na década de setenta, a existência de verdadeiros espaços derivados nos países do Terceiro Mundo (SANTOS, 1978). Estes espaços derivados seriam aqueles onde os processos de modernização e transformação regionais estão diretamente relacionados a anseios externos, às demandas longínquas. Esta reflexão é importante porque nos leva a compreender que tanto a formação quanto as transformações das estruturas territoriais para o trabalho, sobretudo aquelas que aparecem como as mais dinâmicas no interior do território nacional nos países pobres, são, no mais das vezes, portadoras de razões externas e não se voltam para o atendimento das necessidades mais prementes da nação, ou seja, para a solução dos problemas internos.

A cada necessidade imposta pelo sistema em vigor, a resposta foi encontrada, nos países subdesenvolvidos, pela criação de uma nova região ou a transformação das regiões preexistentes. É o que estamos chamando espaço derivado, cujos princípios de organização devem muito mais a uma vontade longínqua do que aos impulsos ou organizações simplesmente locais (SANTOS, 1978, p.104-105).

O caso brasileiro é muito representativo do processo analisado por Milton Santos (1978). A função histórica de produtor de gêneros agrícolas e também de minérios para a metrópole portuguesa e mais tarde para o mercado externo, inseriu o Brasil numa posição sempre subordinada na divisão internacional do trabalho. É do atendimento às demandas longínquas que o próprio território vai tomando forma, ou seja, a composição dos quadros regionais, das infra-estruturas que possibilitam e efetivam a produção agrícola e industrial (e também a exportação desta produção), são obedientes aos mandos de fora, definindo assim "espaços derivados". 
Situações territoriais muito representativas das inserções sempre subordinadas do Brasil nas divisões do trabalho ao longo da história do país podem ser observadas a partir da gênese de regiões e espaços especializados em um tipo de produção que, predominantemente, é voltada para as necessidades do mercado externo.

Algumas destas situações foram bem descritas em análises de importantes intérpretes do Brasil. É o caso do belo trabalho de Gilberto Freyre, escrito em 1937, que analisa a formação, desde o século XVI, daquilo que o autor denomina "civilização do açúcar", designando a força da cultura canavieira de exportação sobre a vida e a paisagem regional do "nordeste açucareiro" (do Recôncavo baiano ao Maranhão, com centro em Pernambuco) (FREYRE, 2004). A exploração do território pela busca de ouro e pedras preciosas nos primeiros séculos do Brasil colônia, nos vastos espaços que se tornariam Minas Gerais e também nos sertões do Brasil central (com todo o esforço necessário para arregimentar mão-de-obra e abrir novos caminhos), foi capaz de criar cidades e formar novas gentes e culturas, tal como relata Darcy Ribeiro $(1995,2006)$. Mais tarde, no final do século XIX será a vez da Amazônia, quando se inicia o estabelecimento de uma região muito ligada às demandas externas pela borracha, produto este que o Brasil detém exclusividade de produção até o início do século XX, criador de uma economia responsável pelo surgimento de cidades modernas e equipadas no interior da floresta (Manaus, Belém), muito mais ligadas à Europa do que ao resto do país (TOCANTINS, 1961).

No célebre trabalho de Pierre Monbeig (1952) podemos também reconhecer, entre o final do século XIX e meados do século XX, uma organização do território brasileiro que, mais uma vez, é orquestrada pela empresa de exportação, com o avanço do cultivo do café pelo interior do estado de São Paulo e adjacências, criando regiões e redes de transporte voltadas para o exterior, via porto de Santos. Outro exemplo é toda uma organização do espaço no sul da Bahia com o cultivo do cacau, processo analisado por Milton Santos (1955) e tão bem retratado no romance de Jorge Amado (1933, 1978). É assim que desenhase um território que toma a forma de um "arquipélago" (BECKER, EGLER, 1992), onde até meados do século XX persistem regiões pouco comunicáveis e "extravertidas", ou seja, regiões cujos nexos que a animam se voltam mais para o exterior do que para a vida nacional.

Para além das feições regionais forjadas no território pelas atividades voltadas ao atendimento das demandas externas, tais atividades e o trabalho alheio às necessidades da nação que elas implicam, foram, no mais das vezes, responsáveis pela própria formação da sociedade e cultura nacionais. $\mathrm{O}$ senhor de engenho do Nordeste açucareiro, o seringalista na Amazônia da produção de borracha, o coronel do cacau no sul da Bahia ou então o usineiro produtor de cana-de-açúcar, cada um deles possui os respectivos tipos e classes sociais que lhes são diretamente subordinados (escravos, seringueiros, trabalhadores da colheita e das barcaças de cacau, bóias-frias cortadores de cana), forjando particularidades não só na exploração do meio geográfico e dos seus recursos, mas também mecanismos específicos de exploração social e de acumulação, o que de fato caracteriza e aprofunda as particularidades regionais. Assim, aspectos culturais locais, trabalho, funções e tipos sociais específicos a cada uma das regiões, bem como a criação das cidades e portos, os movimentos de migração (a demanda por mão-de-obra) e enfim, a própria estrutura social (divisão de classes) e formação cultural das gentes foram, assim, resultados de projetos externos.

No período atual, tão marcado que é pelos imperativos da globalização (SANTOS, 1996, 2000; SILVEIRA, 2002, 2008), como se dão os problemas da subordinação da nação ao projeto externo? No Brasil, persiste o problema de um Estado que não atua de modo a propiciar um planejamento que vise à redução das desigualdades, tornando-se, no mais das vezes, um agente capturado pelas formas de acumulação capitalista, promovendo a expansão das redes e dos fluxos hegemônicos, proporcionando uma "homogeneização" do espaço em favor do capital, tal como analisou Francisco de Oliveira (1977, p.30).

As várias propostas de "integração nacional" que aparecem no Brasil desde meados do século XX, resultaram, quando muito, em ensaios de uma integração que hoje ocorre apenas sob o comando de intenções puramente econômicas e seletivas em termos de classes sociais, o que acaba por gerar mais fragmen- 
tação. A industrialização e a urbanização ocorridas no século XX produziram novas dinâmicas de organização e articulação das regiões e de suas ligações com o mercado externo, além de uma nova organização social do país. A organização do espaço que comporta regiões pouco articuladas dá lugar à uma integração recente do território que, no entanto, é operada por agentes externos e viabiliza, mais uma vez, os nexos com o exterior, facilitando as tarefas de exportação (CASTILLO, 2005).

No Brasil, aos quadros regionais correspondentes às divisões pretéritas do trabalho, serão somadas novas atividades produtivas que os redefinem (com todo o "peso" do trabalho acumulado, que também atua na repartição do trabalho atual). O processo de transformação de uma sociedade que em menos de trinta anos se converte em predominantemente urbana (anos 50 a 70) (SANTOS; SILVEIRA, 2001) e o novo tipo de trabalho por ela desempenhado são fundamentais para a compreensão das dinâmicas atuais de uso do território, que tantas vezes continua politicamente subordinado a projetos externos.

\section{AS FUNÇÕES DO BRASIL NA DIVISÃO INTERNA- CIONAL DO TRABALHO E AS SUAS CONSEQUÊN- CIAS TERRITORIAIS NO PERÍODO ATUAL}

Em que pese a condição ainda subordinada do país no que se refere à sua participação na divisão do trabalho (agora ainda mais internacionalizada), no decorrer do século XX o Brasil conhece um conjunto de transformações econômicas e sociais que lhe conferem status de uma das maiores economias do mundo.

Uma modernização (pós anos 60-70) da atividade agrícola que o coloca entre os principais produtores mundiais de grãos; um processo recente de modernização industrial que lhe confere importante lugar na produção mundial, inclusive de produtos de alta tecnologia (como é o caso, por exemplo, da indústria aeronáutica) e a expansão de atividades modernas de serviços (telecomunicações, financeiros, etc.) que atendem a um dos mercados que mais crescem no mundo.

No entanto, esta modernização e desenvolvimento das forças produtivas (realizada muitas vezes por capitais externos) não são acompanhados de uma melhora significativa das condições de vida para a maior parte da população, e tantas vezes não suprem as necessidades mais essenciais à grande parte da sociedade brasileira que, por sua vez, conhece um processo acelerado de urbanização, uma concentração dos meios de produção, o aumento da escassez e da pobreza (no campo e nas cidades) e uma ampliação sem tamanho da desigualdade e da diferença no consumo de bens e serviços, sobretudo nos maiores centros urbanos.

Estas são as características, e também o resultado, de um processo de desenvolvimento excludente e concentrador que historicamente é praticado e (re) atualizado no território brasileiro. Estes problemas resultam diretamente das opções adotadas pelo país para a sua inserção, de certo modo passiva e orientada por agentes políticos e econômicos internos e externos, na divisão internacional do trabalho.

Hoje, com o processo de globalização, resultado e resultante das condições materiais próprias do meio técnico-científico-informacional (SANTOS, 1996, 2000), a divisão internacional do trabalho se multiplica e é tornada muito mais complexa. $\mathrm{O}$ desenvolvimento técnico-científico acumulado durante o século XX confere a emergência de novos sistemas produtivos que funcionam em rede, por meio do qual alguns seletos agentes da economia podem fazer um uso intensivo e diferencial do território (SANTOS, 1999). Disto decorre uma nova distribuição do trabalho, que é agora re-dividido (e re-articulado) em diferentes pontos do planeta. As novas possibilidades de transporte (permitindo maior fluidez) e da informação (permitindo controle e tomadas de decisão à distância) redistribuem o trabalho de grandes empresas (inclusive os de caráter tecnológico) por países pobres e que antes figuravam como fornecedores de gêneros agrícolas. No entanto, os investimentos produtivos de grandes grupos econômicos em países com posição subordinada na divisão internacional do trabalho significam, muitas vezes, apenas a exploração de novos mercados ou a inserção de uma produção voltada em sua maioria para o mercado externo, reforçando mais uma vez os nexos de dependência.

Assim, é pelo trabalho realizado por multinacionais de diferentes setores produtivos que países como o Brasil aparecem hoje com uma maior partici- 
pação na divisão internacional do trabalho, ainda que esta participação não garanta distribuição interna dos recursos. Estes recursos criados por esta maior participação (de certo modo artificial e desnecessária) no trabalho e na produção mundiais, não são convertidos em recursos vantajosos para a totalidade da nação e muitas vezes acabam agravando as disparidades sociais e a fragmentação do território nacional.

Um resultado deste processo é o surgimento de enclaves espaciais onde atividades agrícolas modernas ou atividades industriais de alta tecnologia e voltadas para a exportação ocorrem de forma concentrada, configurando cidades e regiões especializadas em determinado tipo de produção. O geógrafo uruguaio Germán Wettstein (1992, p.39) chega a falar da existência, nos territórios nacionais dos países subdesenvolvidos, de verdadeiras "regiões fictícias", justamente porque não são organizadas a partir das demandas locais, regiões que se estruturam em função de reclamos longínquos. É assim, por exemplo, que a atividade industrial brasileira, sobretudo aquela mais intensa em capital e tecnologia, encontra-se restrita a espaços que atendem às exigências do capital externo, localizando-se, ainda hoje, sobretudo na Região Concentrada do país (SANTOS; RIBEIRO, 1979, SANTOS; SILVEIRA, 2001).

A indústria brasileira moderna de exportação localiza-se em áreas como a capital paulista e seu entorno, o Vale do Paraíba-SP, a região de Campinas-SP, ainda que a indústria automobilística, por exemplo, tenha conhecido certa desconcentração (em função da "guerra dos lugares" acirrada pelas políticas de isenção fiscal). Estes pólos da produção tecnológica e intensa em capital no mais das vezes resultam das políticas de incentivos territoriais que atendem especialmente aos interesses de empresas que buscam no país oportunidades baratas de produção para exportação, e mais uma vez atestam uma participação na divisão internacional do trabalho arraigada às intenções dos agentes externos.

Frente a estas condições, o trabalho e os recursos mobilizados pelo mercado interno aparecem como residuais às políticas do Estado, ainda que tomem força no conjunto da nação, estabelecendo outras formas de uso do território.

No Brasil, o trabalho e a produção exclusiva- mente voltados para o mercado interno se distribuem também de forma não homogênea no território, alcançando áreas e pontos que nem sempre interessam ao capital e às finanças hegemônicos. É assim que, frente a uma mobilização de trabalhadores, lugares e recursos que é praticada pelos agentes hegemônicos da economia, uma divisão interna (doméstica) do trabalho é praticada por grande parte da população e de empresas, com alcances apenas locais ou regionais. É assim que à divisão do trabalho hegemônica e despótica imposta de fora ("e de cima"), se opõe, dialeticamente, uma divisão interna do trabalho que emerge "de baixo" (SANTOS, 2000; SANTOS; SILVEIRA, 2001). Assim, no interior do território da nação, divisões muito diferentes do trabalho se sobrepõem e são superpostas (SANTOS, 1996, p.109), atendendo ora aos interesses do mercado internacional, ora às demandas mais diretas e necessárias dos lugares.

Este descompasso na organização do trabalho e do território resulta da divergência entre agentes por demais diferenciados quanto à mobilização dos recursos e, para o que mais nos interessa, são agentes com naturezas e poderes extremamente desiguais no que se refere, por exemplo, ao atendimento das suas necessidades (infra-estrutura, crédito, normas) pelas "políticas públicas" (que hoje mais atendem aos interesses privados), denunciando, mais uma vez, fragmentação e uso desigual e corporativo do território. É a produção de um território nacional instável e fracionado (SANTOS, 1978; SANTOS; SILVEIRA, 2001; SILVEIRA, 2002), sobretudo nas regiões ou lugares que parecem, à primeira vista, como "espaços modernizados", mas cujos comandos políticos têm origem em pólos externos.

\section{ALGUMAS TENDÊNCIAS RECENTES DA PRODU- ÇÃO AGRÍCOLA DE EXPORTAÇÃO}

O agronegócio de exportação, da forma como é hoje praticado no Brasil, exemplifica o caráter subordinado da participação do país na divisão internacional do trabalho. Ainda que em termos de geração de divisas a exportação da produção industrial ultrapasse a agrícola, as exportações do campo brasileiro compõem neste início de século parte importante de nossa participação no mercado externo. 
A crescente demanda mundial por produtos como a soja, milho, derivados de cana-de-açúcar e outras commodities têm transformado por completo o uso agrícola do território brasileiro nas últimas décadas. Uma forte política agrícola voltada para produção das commodities mais valorizadas no mercado externo de certo modo reafirma a posição do Brasil como país agroexportador na atual divisão internacional do trabalho.

A ação de grupos econômicos estrangeiros na atividade agrícola moderna (no mais das vezes com amplo apoio do poder público) impulsionou a produção de grãos e derivados, tornando o Brasil um dos principais produtores mundiais destes gêneros. No entanto, os circuitos produtivos das principais commodities agrícolas estão sob o comando exclusivo de grupos econômicos internacionais (Cargill, Bunge, ADM, Monsanto, etc.) ou de alguns poucos grupos nacionais que praticam as mesmas lógicas globais de produção (como é o caso do Grupo André Maggi). A ação destes grupos hegemônicos no Brasil tem ocasionado importante reordenação do território no interior do país, com o surgimento de novos fronts agrícolas nos cerrados de Mato Grosso, Bahia, Piauí, Maranhão e mesmo na Amazônia, ou ainda, ocasionado o surgimento das modernas "cidades do campo" (SANTOS, 1988, 2000). Regiões produtivas modernas (extremamente especializadas) e muito funcionais às demandas externas se constituem no interior do país, mas, por este mesmo motivo, são muito vulneráveis às demandas do mercado internacional (CASTILLO, 2005).

Como o produto cultivado determina claramente a forma de propriedade da terra, o agronegócio de exportação tende a estimular a monocultura, o latifúndio e a exploração capitalista da agricultura (OLIVEIRA; STÉDILE, 2005) e mais uma vez o resultado deste processo é a emergência de especializações territoriais alienadas e estranhas ao cotidiano da nação.

A participação do Brasil como país agroexportador na divisão internacional do trabalho ganha ainda mais força nestes primeiros anos do século atual com as políticas de produção dos chamados biocombustíveis, demandando maior produção agrícola para a exportação de commodities. O recente crescimento da área produzida e da produtividade da cana-de-açúcar (ou de etanol?) em diversas unidades da federação atesta a tendência subordinada do país na divisão internacional do trabalho, resultando numa atividade que se volta em grande parte para o mercado externo.

É por isso que novas áreas cultivadas e um novo conjunto de unidades produtivas (grandes usinas) e objetos técnicos voltados para o processamento da cana-de-açúcar aparecem de norte a sul do Brasil, especialmente no Centro-Sul do país, mas também em novas áreas localizadas até mesmo no interior da Amazônia. A crescente demanda pelos chamados biocombustíveis deve fazer com que grandes extensões de terra sejam, nos próximos anos, voltadas para a produção de etanol (álcool combustível) a partir da cana, na idéia de que o país, potencialmente, se torne o principal fornecedor mundial deste combustível (QUADRO 1).

O Estado de São Paulo continua sendo o maior produtor do país, onde se encontram também as maiores usinas de processamento da cana-de-açúcar. Conforme dados da União da Indústria de Cana-de-açúcar (UNICA) e do Ministério da Agricultura, Pecuária e Abastecimento (MAPA), o volume da produção realizada em São Paulo dobrou entre 2001 e 2008, alcançando praticamente 300 milhões de toneladas, o que representa mais da metade da produção nacional (UNICA, 2009).

Para além de deixar em segundo plano impor-

\begin{tabular}{|c|c|c|c|}
\hline Safra & $2003 / 2004$ & $2005 / 2006$ & $2007 / 2008$ \\
\hline Região Centro-Sul & 299.120 .591 & 337.714 .418 & 431.113 .603 \\
\hline Regiões Norte e Nordeste & 60.194 .968 & 49.727 .458 & 64.609 .676 \\
\hline Brasil (total) & 359.315 .559 & 387.441 .876 & 495.723 .279 \\
\hline
\end{tabular}

QUADRO 1: Crescimento recente da produção de cana-de-açúcar no Brasil (em toneladas)

Fonte: UNICA/MAPA 
tantes necessidades internas como a produção de gêneros alimentícios que continuam sendo importados, a expansão do cultivo da cana-de-açúcar é realizada de forma corporativa, e atende mais aos interesses de agentes privados do que aos interesses da nação. Neste início de século, quando o álcool combustível (agora "etanol"), produto que o Brasil detém tecnologia e liderança de produção, torna-se commodity valorizada (e globalizada) no mercado internacional, o país deixa de regular os preços da própria produção, perde o poder de regulação sobre o que produz. O aumento da produção, mais uma vez, não significa poder de barganha no mercado internacional, nem mesmo garantia de preço acessível e estável para o mercado interno.

Assim, o caso do etanol parece ser mais uma ocasião para o reforço da subordinação do país às demandas do mercado internacional, em detrimento de uma produção socialmente necessária, ou seja, uma produção que de fato seja voltada para o mercado interno e para as demandas mais urgentes da nação. Fala-se atualmente em crise de alimentos, quando o que se trata, na verdade, é de uma crise da sua distribuição e sobretudo de uma política perversa que privilegia a produção e a exportação de commodities agrícolas valorizadas no mercado internacional, política esta que é feita, portanto, em privilégio de alguns. O caso brasileiro é também exemplar deste problema político grave, já que o aumento da produção agrícola é normalmente acompanhado do aumento da miséria e da fome (CARNEIRO; PEREIRA, 2005). Fala-se hoje em "segurança alimentar", pretensão necessária apenas às nações pobres, justamente porque tais nações não são capazes de exercer a total soberania sobre o seu território, ou seja, falta aos países pobres liberdade para produzir o que mais precisam, no seu próprio chão.

\section{ALGUMAS CONSIDERAÇÕES FINAIS}

Tal como afirma Milton Santos, "A divisão internacional do trabalho é processo cujo resultado é a divisão territorial do trabalho" (SANTOS, 1996, p.106) e é somente nesta perspectiva que a geografia pode contribuir para a sua compreensão. "Essa divisão territorial do trabalho cria uma hierarquia entre lugares e, segundo a sua distribuição espacial, redefine a capacidade de agir de pessoas, firmas e instituições" (SANTOS, 1996, p.108), ou seja, toda a formação do território é ditada e ritmada pela parcela de trabalho que o país desempenha no sistema internacional, e também pelo trabalho que cada região acolhe no espaço da nação.

A divisão internacional do trabalho apenas nos dá a maneira de ser do modo de produção dominante, apontando as formas geográficas portadoras de uma inovação e, por isso mesmo, carregadas de uma intencionalidade nova. É através da incidência num país da divisão interna do trabalho que as especificidades começam a repontar: a formação sócio-econômica correspondente atribui um valor determinado a cada forma e a todas as formas, através da redistribuição de funções (SANTOS, 1978, 2005, p.61).

As inserções do Brasil na divisão internacional do trabalho, ou seja, as funções desempenhadas por nosso país no sistema mundial conferem, historicamente, uma condição de subordinação da nação aos interesses externos, enquanto o trabalho e os recursos voltados para o mercado interno aparecem como residuais aos olhos das políticas públicas.

Deste processo, resulta um planejamento que operacionaliza formas e funções territoriais no mais das vezes estranhas e que não suprem as necessidades cotidianas da sociedade. Daí a emergência de "regiões" e eixos produtivos que em sua maior parte convergem para o exterior (CASTILLO, 2005), desestabilizando o território nacional que se torna cada vez mais vulnerável.

Pode-se concluir que as posturas políticas que dão suporte e legitimidade às funções desempenhadas pelo Brasil na divisão internacional do trabalho são, ainda nos dias de hoje, o motor da fragmentação e da produção das desigualdades no território. Um imperativo da fluidez territorial e da produção para a inserção desenfreada num mercado externo regulado pela moeda internacional, regido por um capital financeiro globalizado e prenhe de uma competitividade despótica e sem compromisso moral com a nação revela as tantas práticas e posturas políticas enviesadas. Como 
vencer tais imperativos? As palavras de María Laura Silveira indicam tarefas necessárias e caminhos possíveis:

Construir um Estado que possa aglutinar sem matar a liberdade, que possa cuidar da cidadania, cooperando na produção de um sentido local e nacional, que possa fortalecer as solidariedades sem impor soluções domesticadas ou "folclorizadas" será uma das etapas de um projeto transformador, pois uma nação de cidadãos não virá com mais velocidade e fluidez, senão com uma vida mais lenta, ancorada na solidariedade orgânica que permita uma planificação social e socializante (SILVEIRA, 2008, p.18, tradução nossa).

É preciso ensaiarmos a compreensão das forças antagônicas que colaboram para manter a estrutura perversa do poder sobre os países pobres, cujo uso despótico e interesseiro do território brasileiro é caso exemplar. A compreensão destes mecanismos hegemônicos de poder é peça essencial para pensarmos projetos para um futuro outro, onde o território seja capaz de suprir em primeiro lugar as suas próprias demandas, com usos endereçados à totalidade da nação.

\section{REFERÊNCIAS}

AMADO, J. Cacau (romance). 32. ed. Rio de Janeiro: Record, 1978 [1933].

BECKER, B. K.; EGLER, C. G. Brasil: uma nova potência regional na economia mundo. 4. ed. Rio de Janeiro: Bertrand Brasil, 2003 [1992].

CARNEIRO, P. A. S.; PEREIRA, M. F. V. Território da desigualdade: pobreza, fome e concentração fundiária no Brasil contemporâneo. Geografia. Rio Claro, v. 30, n. 2, p.255-269, 2005.

CASTILLO, R. Exportar alimentos é a saída para o Brasil? O caso do complexo soja. In: ALBUQUERQUE, E. S. (Org.). Que país é esse? Pensando o Brasil contemporâneo. São Paulo: Globo, 2005. p. 283-307. FREYRE, G. Nordeste. Aspectos da influência da cana sobre a vida e a paisagem do Nordeste do Brasil. São Paulo: Global, 2004 [1937].

MONBEIG, P. Pionniers et planteurs de São Paulo. Paris: Armand Colin, 1952.

OLIVEIRA, F. de. Elegia para uma re(li)gião. Sudene, Nordeste, Planejamento e Conflitos de Classes. São Paulo: Paz e Terra, 1977.

OLIVEIRA, A. U. de; STEDILE, J. P. A natureza do agronegócio no Brasil. Brasília: Via Campesina, 2005.

RIBEIRO, D. O povo brasileiro. São Paulo: Companhia das Letras, 2006 [1995].

SANTOS, M. Zona do cacau, introdução ao estudo geográfico. Salvador: Imprensa Oficial da Bahia, 1955.

. O trabalho do geógrafo no Terceiro Mundo. São Paulo: Hucitec, 1978.

- Metamorfoses do espaço habitado. Fundamentos teóricos e metodológicos da geografia. São Paulo: Hucitec, 1988.

. A Natureza do Espaço. Técnica e Tempo. Razão e Emoção. São Paulo: Hucitec, 1996.

Modo de produção técnico científico e diferenciação espacial. Território. Rio de Janeiro, Ano IV, n.6, p. 5-20, 1999.

. Por uma outra globalização. Do pensamento único à consciência universal. Rio de Janeiro: Record, 2000 .

. A divisão social do trabalho como uma nova pista para o estudo da organização espacial e da urbanização nos países subdesenvolvidos. In: SANTOS, M. Da totalidade ao lugar. São Paulo: Edusp, 2005. cap.3, p.55-75.

SANTOS, M.; RIBEIRO, A. C. T. O conceito de Re- 
gião Concentrada. UFRJ, IPPUR, Departamento de Geografia, 1979 (mimeo).

SANTOS, M.; SILVEIRA, M. L. O Brasil: território e sociedade no início do século XXI. Rio de Janeiro: Record, 2001.

SILVEIRA, M. L. Uma globalização desnecessária, um território instável. Ciência Geográfica. Bauru, ano VII, v. 1 (21), p.43-46, 2002.

Globalización y território usado: imperativos y solidaridades. Cuadernos del Cendes. Caracas, ano 25, n.69, p.1-19, 2008.

TOCANTINS, L. O rio comanda a vida: uma interpretação da Amazônia. 2. ed. Rio de Janeiro: Civilização Brasileira, 1961 [1952].

UNICA - União da Indústria de Cana-de-Açúcar (sítio na internet). Disponível em $<$ http://www.unica. com.br>. Acesso em nov.de 2009.

WETTSTEIN, G. Subdesenvolvimento e Geografia. São Paulo: Contexto, 1992. 